\title{
Degloving Injury: Different Ways of Management
}

\author{
Nakarmi KK ${ }^{1}$, Shrestha SP ${ }^{2}$
}

\begin{abstract}
Degloving injury involves shearing of the skin from the underlying tissue due to differential gliding in response to the tangential force applied to the surface of the body leading to disruption of all the blood vessels connected to skin. The flap of degloved skin has precarious blood supply making it almost impossible for the flap to survive. We describe two cases of degloving of thigh managed differently in different settings.
\end{abstract}

Keywords: Degloving; excision; split skin graft

\section{INTRODUCTION}

Degloving injuries occur when there is sufficient tangential force to a body surface to disrupt the structures connecting skin and subcutaneous tissues to the superficial fascia. There may also be associated injuries to the underlying soft tissues, bone, nerves and vessels. It involves the young males, and most are related to road traffic accident constituting upto $4 \%$ of all the trauma related admissions. Treatment guidelines are not clear $^{1}$. The injury may be so severe that the limb is non-viable and requires amputation. It has been classified into three group based on whether only skin, underlying soft tissue or bone is involved in the injury process ${ }^{2}$.

Different modalities of treatment are described. It includes excision and secondary skin grafting with split or full thickness skin grafts. Immediate split skin grafting by graft derived from the degloved skin flap or other parts of the body is also done if patient is in stable condition. Other methods include treatment with cryopreserved split-thickness skin grafts harvested from degloved flap, artificial dermal replacement and vacuumassisted closure ${ }^{3}$. Dermal regeneration template (Integra) has been used in association with a sensate neurovascular fasciocutaneous pedicled flap salvaged from the non-viable lower leg to reconstruct the defect ${ }^{4}$. Aggressive debridement aided by fluorescein vital dye staining followed by primary or delayed wound closure guided by local and systemic conditions is advocated by some ${ }^{5}$.

Early plastic surgery evaluation and management of these patients have been associated with lesser number of surgeries and shorter hospital stay ${ }^{6}$. Clinical evaluation aided by use of

1. Dr. Kiran K. Nakarmi

2. Dr. Sikshya Prakash Shrestha

Address for correspondence:

Dr. Kiran K. Nakarmi

Department of Burns, Plastic and Reconstructive Surgery

Kirtipur Hospital. Kirtipur, Nepal

Email: kknakarmi@yahoo.com fluorescein dye to assess the flap viability will guide whether skin can be harvested from the flap which can be stored for later use if general condition does not allow immediate grafting7. Use of the degloved flap after defatting along with negative pressure wound therapy has also been described8.

\section{CASES}

\section{Case 1}

Eighteen year old girl was run over by a car. She had degloving of whole circumference of the upper half of right thigh. She was initially managed in a private hospital outside Kathmandu. The wound was irrigated and flap was sutured in place before sending the patient to Kirtipur Hospital. When she came to us, the skin flap was already black and necrosed (Figure 1). It was excised completely. Wound was dressed daily for few days. Split skin graft was applied to cover the wound afterwards. She got discharged from the hospital in three weeks time after full recovery.

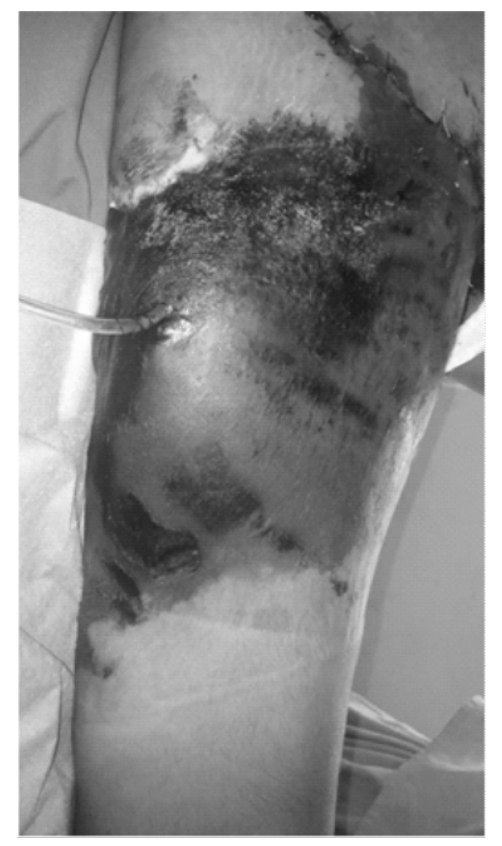

Figure 1: Necrosed skin several days after degloving 


\section{Case 2:}

Twenty nine year old man fell off the scooter he was riding. He landed on his right thigh and ripped off most of the thigh skin (Figure 2). He presented to Madhyapur Hospital immediately after the accident. He did not have any other injury except diastasis of the symphysis pubis. He was taken to operation theater within few hours. His wound was thoroughly washed. Split skin graft was harvested from the degloved skin before excising it and applied to the defect in the same setting. Pubic diastasis was fixed after two weeks. He fully recovered and went home in one month's time (Figure 3).

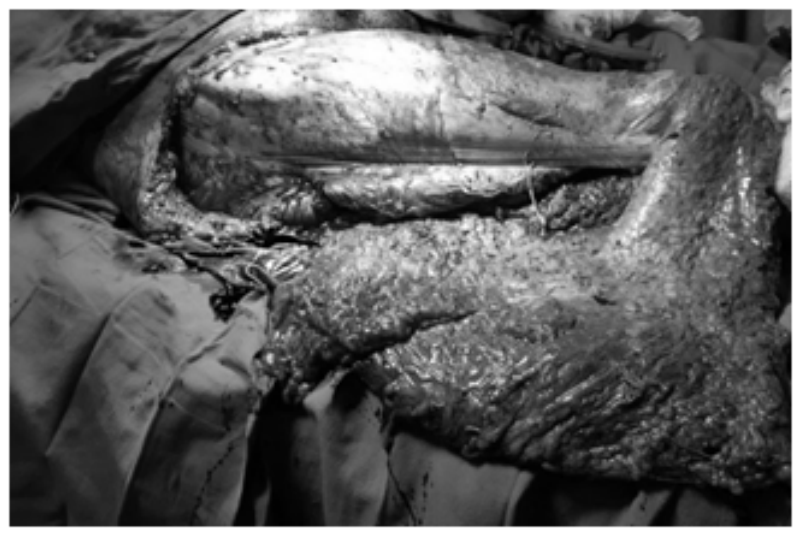

Figure 2: Degloved flap turned inside out

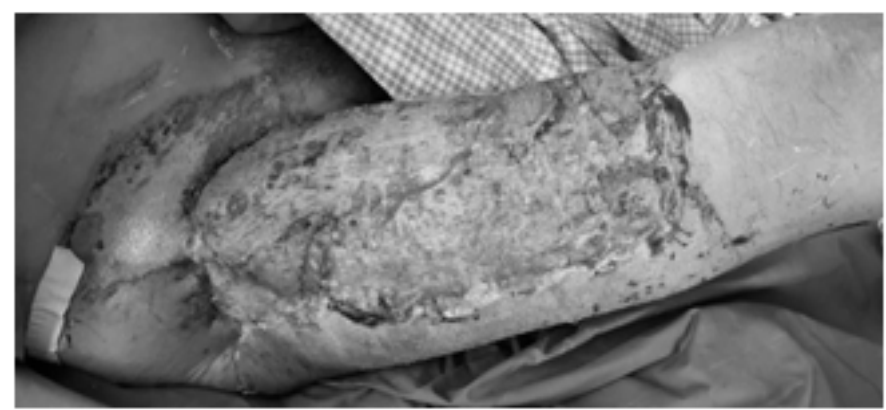

Figure 3: Grafted area after two weeks

\section{DISCUSSION}

There is no clear guideline for the treatment of degloving injury. (1) Management depends on the local as well as general conditions of the patient. Immediate reconstruction can be considered if the patient is in stable condition. Otherwise skin graft can be harvested from the flap and stored for later use when the patient becomes stable.(7) The first case in our series needed skin harvesting from the other thigh because the flap had already necrosed. However, it was possible to use the skin graft from the flap in the second case because of the early presentation which obviated the need of harvesting graft from other part of the body. However, associated bony injury led to the delay in recovery.
Degloving injury can present at different times. Management should be tailored depending on the extent and type of injury, time of presentation and associated injuries.

\section{REFERENCES}

1. Hakim S, Ahmed K, El-Menyar A, Jabbour G, Peralta R, Nabir S, et al. Patterns and management of degloving injuries: a single national level 1 trauma center experience. World J Emerg Surg. 2016;11:35.

2. Yan H, Gao W, Li Z, Wang C, Liu S, Zhang F, et al. The management of degloving injury of lower extremities: technical refinement and classification. J Trauma Acute Care Surg. 2013;74(2):604-10.

3. Dini M, Quercioli F, Mori A, Romano GF, Lee AQ, Agostini T. Vacuum-assisted closure, dermal regeneration template and degloved cryopreserved skin as useful tools in subtotal degloving of the lower limb. Injury. 2012;43(6):957-9.

4. Greig A, Angel J, Jones N, Healy C. The use of Integra with a sensate fasciocutaneous pedicled flap for the salvage reconstruction of a below knee amputation after pedestrian vs train multi-planar degloving injury. J Plast Reconstr Aesthet Surg. 2010;63(1):e3840.

5. Mandel MA. The management of lower extremity degloving injuries. Ann Plast Surg. 1981;6(1):1-5.

6. Mello DF, Assef JC, Soldá SC, Helene A. Degloving injuries of trunk and limbs: comparison of outcomes of early versus delayed assessment by the plastic surgery team. Rev Col Bras Cir. 2015;42(3):143-8.

7. Milcheski DA, Ferreira MC, Nakamoto HA, Tuma P, Gemperli R. [Degloving injuries of lower extremity--proposal of a treatment protocol]. Rev Col Bras Cir. 2010;37(3):199-203.

8. Sakai G, Suzuki T, Hishikawa T, Shirai Y, Kurozumi T, Shindo M. Primary reattachment of avulsed skin flaps with negative pressure wound therapy in degloving injuries of the lower extremity. Injury. 2017;48(1):137-41.

\section{CONCLUSION}

